\title{
Ineffective Breathing Pattern: Defining Characteristics in Children With Acute Respiratory Infection
}

\author{
Livia Maia Pascoal, RN, Marcos Venícios de Oliveira Lopes, RN, PhD, Viviane Martins da Silva, RN, PhD, \\ Beatriz Amorim Beltrão, RN, Daniel Bruno Resende Chaves, RN, Juliana Maria Vieira de Santiago, RN, and \\ T. Heather Herdman, RN, PhD, FNI
}

Livia Maia Pascoal, RN, is a Master's Degree, Nursing Professor at Federal University of Maranhão in Imperatriz, Brazil; Marcos Venícios de Oliveira Lopes, RN, PhD, is a Nursing Professor; Viviane Martins da Silva, RN, PhD, is a Nursing Professor; Beatriz Amorim Beltrão, RN, is a Doctoral Student; Daniel Bruno Resende Chaves, RN, is a Doctoral Student; Juliana Maria Vieira de Santiago, RN, is a Master's Student at Federal University of Ceará in Fortaleza, Brazil; and T. Heather Herdman, RN, PhD, FNI, is a Visiting Professor at Federal University of Ceará in Fortaleza, Brazil and the CEO/Executive Director of NANDA International, Inc., Kaukauna, Wisconsin.

\section{Search terms:}

Children, ineffective breathing pattern, nursing assessment, nursing diagnosis, respiratory sign and symptom

\section{Termos de busca:}

Padrão respiratório ineficaz, crianças, avaliação de enfermagem, diagnóstico de enfermagem, sinais e sintomas respiratórios

\section{Author contact:}

marcos@ufc.br, with a copy to the Editor: journal@nanda.org

Financial support: Coordenação de aperfeiçoamento de pessoal de nível superior (CAPES) process number BEX12605/12-3.
PURPOSE: To determine the accuracy of NANDA-I defining characteristics for the nursing diagnosis, ineffective breathing pattern, in children with acute respiratory infection.

METHODS: This was a prospective cohort study in 136 children. Measures of accuracy were calculated for the defining characteristics.

FINDINGS: Use of accessory muscles to breathe presented the best measure of accuracy. Alterations in depth of breathing presented a high value of sensitivity. Altered chest excursion and orthopnea presented high values of specificity.

CONCLUSIONS: Use of accessory muscles to breathe showed the best predictive capacity for ineffective breathing pattern.

IMPLICATIONS FOR NURSING PRACTICE: Measures of accuracy can contribute to an accurate diagnostic inference process, improving patient assessment and facilitating rapid, accurate diagnosis.

OBJETIVO: Determinar a acurácia das características definidoras para o diagnóstico de enfermagem Padrão respiratório ineficaz em crianças com infecção respiratória aguda.

MÉTODOS: Este foi um estudo de coorte prospectiva aberta com um grupo de 136 crianças. Medidas de acurácia foram calculadas para as características definidoras.

RESULTADOS: Uso de musculatura acessória para respirar apresentou a melhor medida de acurácia. Alteração na profundidade respiratória apresentou elevado valor de sensibilidade. Excursão torácica alterada e Ortopneia apresentaram altos valores de especificidade.

CONCLUSÃO: Uso de musculatura acessória para respirar apresentou melhor capacidade preditiva para Padrão respiratório ineficaz.

IMPLICAÇõES PARA A PRÁTICA DE ENFERMAGEM: Medidas de acurácia podem contribuir para um processo de inferência diagnostica acurado. Educadores podem usar o conhecimento de características definidoras críticas para ensinar aos alunos técnicas de avaliação adequadas, e os enfermeiros na prática clínica podem estar mais atentos a essas características, a fim de facilitar o diagnóstico rápido e preciso. Pesquisa adicional deve procurar replicar esse trabalho em populações semelhantes e diferentes, e identificar as características do diagnóstico ao longo do tempo. 
NANDA-I (2012) defines nursing diagnosis as a clinical judgment about actual or potential individual, family, group, or community responses to health conditions or life processes. The lack of knowledge about the components of nursing diagnosis (definitions, defining characteristics, and related factors, or risk factors) presents a patient safety risk and makes it impossible to ensure diagnostic accuracy (Herdman \& Von Krogh, 2012). For most diagnoses, a single piece of clinical assessment data is not sufficient to confirm the presence of a nursing diagnosis. Diagnostic accuracy requires nurses to cluster assessment data through the use of clinical judgment as a basis for determining priority foci of care, setting appropriate outcomes, and selecting evidence-based interventions. Thus, nurses usually identify a set of defining characteristics and verify a plausible relationship between the diagnostic hypotheses of a specific situation and the characteristics presented by the patient (Lopes, Silva, \& Araujo, 2012). It is, therefore, critical for nurses to understand the concepts that underlie each nursing diagnosis, and to understand the diagnostic indicators necessary for the accurate diagnosis of their patients.

It has been 30 years since Dr. Marjory Gordon (1982, 1987) discussed the need to identify critical defining characteristics of nursing diagnoses: those that must be present in order to diagnose an actual or potential human response. She also discussed the necessity for reliability studies to identify clusters of assessment data (cues) that were reliable for accurate diagnosis. However, research remains scarce as to those defining characteristics that most commonly occur in patient populations and those that are required for accuracy in diagnosis.

Much of the research on defining characteristics in nursing diagnosis has focused on the diagnostic content validation method of Fehring (1986, 1987, 1994); others have used magnitude estimation scaling (Kinney \& Guzzetta, 1989) and identification of clinical referents for nursing diagnosis (Grant \& Kinney, 1992). More recently, studies have evolved that utilize the Rasch method to test instrument development within nursing diagnosis and health care in general (Vargas, 2011; Yorke, Horton, \& Jones, 2012), and a strategy for assessing the accuracy of the defining characteristics based on the approach used to determine accuracy of diagnostic tests (Beltrão, Silva, Araujo, \& Lopes, 2011; Silva, Lopes, Araujo, Ciol, \& Carvalho, 2008; Sousa et al., 2013).

In this latter strategy, each defining characteristic is treated as a diagnostic test, which modifies the estimate of the probability of a diagnosis to be present in a given situation. Thus, the accuracy of a defining characteristic is defined as the ability of this characteristic to correctly differentiate between individuals with and without a nursing diagnosis (Lopes et al., 2012). Therefore, measures of sensitivity (Se), specificity (Sp), and positive ( $\mathrm{PV}+$ ) and negative predictive values (PV-) are used to describe the diagnostic accuracy of the defining characteristics (diagnostic tests, in the context of this research; Knottnerus \& Buntinx, 2009).
Among the multiple nursing diagnoses from NANDA-I, many studies have highlighted those related to the respiratory system. The diagnoses of impaired gas exchange (00030-IGE), ineffective airway clearance (00031-IAC), and ineffective breathing pattern (00032-IBP) have been frequently cited in the literature in different clinical situations and age groups (Silva et al., 2011). In a previous study that sought to analyze the nursing diagnoses present in children with respiratory signs and symptoms, IBP was identified in $80 \%$ of the sample. Among the defining characteristics, alterations in depth of breathing and use of accessory muscles to breathe presented statistically significant associations for that nursing diagnosis (Chagas, Lima, Oliveira, \& Luz, 2011).

In another study that evaluated children with acute respiratory infection (ARI), IBP was identified in $74.4 \%$ of the sample. Dyspnea was the most frequent defining characteristic $(74.4 \%)$, but other characteristics were also highlighted, such as tachypnea (32.1\%) and use of accessory muscles to breathe (25.6\%; Monteiro, Silva, \& Lopes, 2006). Although the ARI's are strongly related to the occurrence of respiratory nursing diagnosis, studies of accuracy related to this theme were not found in the literature.

ARI is the most common type of respiratory infection in childhood and creates changes that affect the functioning of the respiratory system. Pneumonia is an example of this type of infection, occurring when the defense mechanisms of the respiratory system fail to maintain a sterile respiratory tract, causing obstruction of the bronchioles and alveoli with fibrotic exudate (Tarantino, 2005). This clinical condition can lead to several complications, such as damage to the gas exchange process, difficulties in the pulmonary ventilation process, and atelectasis (Martins \& Gutiérrez, 2005).

Because of the imperative to improve the accuracy of the nursing diagnosis reasoning process, the objective of this study was to analyze the accuracy of the defining characteristics of the nursing diagnosis, ineffective breathing pattern, in children with ARI.

\section{Methods}

A group of 136 children with ARI were followed in a prospective cohort study for a period ranging from 6 to 10 consecutive days to verify the occurrence of IBP. The study was conducted in Northeastern Brazil, in two public hospitals specializing in pediatrics. Approval for this study was obtained from the ethics committee of the institutions where the research was performed. Parents were informed about the study, and signed the terms of free and informed consent prior to data collection.

Children who had been admitted for a period of less than $48 \mathrm{hr}$, and who were between 0 and 5 years of age, were included in this study. Physicians practicing at the institution diagnosed the ARI, which included pneumonia, bronchiolitis, sinusitis, pharyngitis, and tonsillitis. Children were excluded if they were not hospitalized for a minimum of 6 


\section{Ineffective Breathing Pattern}

days, or if they presented with diseases that could change the specific clinical condition of ARI (e.g., congenital heart disease, cerebral palsy).

The sample size was calculated based on a confidence level of $95 \%$, a sensitivity of $80 \%$, a desired width of $8 \%$ of the confidence intervals constructed, and an estimated prevalence of $74.4 \%$ according to a previous study (Monteiro et al., 2006). According to these parameters, a minimum of 130 children was required for the sample. Ultimately, the final sample consisted of 136 consecutively sampled children. Because these children were evaluated for a period of between 6 and 10 consecutive days, the total number of assessments was 1,128.

\section{Data Collection Instruments}

An instrument including the defining characteristics of IBP was developed in accordance with the NANDA-I terminology (Herdman, 2012) and based on literature about pulmonary evaluation (Jarvis, 2011; Potter \& Perry, 2004; Swartz, 2005). This instrument also included other information about the children, including gender, medical diagnosis, number of hospitalizations, date of birth, and date of admission. Operational definitions were created for each defining characteristic to be studied, and data were collected by trained members of a research group in nursing diagnosis. This training lasted $8 \mathrm{hr}$ and included a theoretical discussion of diagnostic methods and operational definitions that would be used in data collection. It also included an assessment of the clinical evaluation skills using six children of similar ages to the research sample. Once competency was assured, we proceeded with data collection.

\section{Diagnostic Inference Training}

Nurses from the same research group were selected to participate in the diagnostic inference process. Initially, these nurses were trained to recognize the presence or absence of the IBP nursing diagnosis based on a review of defining characteristics. Once the team members reached consensus as to what would constitute a diagnosis of IBP and what would not, they were then assessed for their ability to correctly diagnose subjects with or without IBP based on an analysis of 12 fictitious clinical cases. The aim of this strategy was to enable these nurses to achieve the same level of ability in the diagnostic inference process, as would be evident in their ability to diagnose these cases consistently and uniformly (Lopes et al., 2012). Ten nurses participated in this stage; once competency was confirmed in the diagnosis of IBP, analysis of the collected assessments was initiated.

All assessments obtained $(1,128)$ were divided into five blocks containing approximately 226 clinical cases each. The five blocks were then evaluated by five different pairs of nurses to determine the presence or absence of IBP. Each nurse pair independently made the diagnostic inference, based on all evaluations made of each child over the
L. M. Pascoal et al.

period of his or her hospitalization. The agreement between nurses, measured by the kappa coefficient, was 0.7307 ( $z=$ $53.58, p<.001)$, which was considered strong, according to Kestenbaum (2009). In cases in which there was discordance of opinion about the presence of IBP $(n=251,22.25 \%$ of cases), the determination about its presence or absence was made by the research team, based on an analysis of the assessments.

\section{Data Analysis}

Statistical analysis was performed with the support of the R software, version 2.12.1 (R Foundation for Statistical Computing, Vienna, Austria). The generalized estimating equation model (GEE) was adjusted to evaluate the association between each defining characteristic and the presence of the IBP nursing diagnosis. This method allowed the analysis of all evaluations of this nursing diagnosis per child, considering the correlation between the repeated measurements. The GEE model used a structure called the firstorder autoregressive correlation, which assumes that the presence of each diagnostic assessment is correlated with the presence of this diagnosis in the previous assessment (Van Belle, Fisher, Heagerty, \& Lumley, 2004). The characteristics that were associated with the nursing diagnosis, according to the GEE model, were evaluated according to measures of accuracy.

The accuracy of defining characteristics was based on measures of Se, Sp, PVs (positive and negative), likelihood ratio (positive and negative), and diagnostic odds ratio (OR; see Table 1). The quality of the defining characteristics was evaluated from the confidence intervals using the positive and negative likelihood ratio. In this case, the defining characteristic was considered accurate when the confidence interval did not include the value of 1.00 .

In this study, these measures were defined based on the description given by Lopes et al. (2012). Se represents the probability of a defining characteristic being present in patients with the diagnosis in question. Sp represents the probability of the absence of a defining characteristic in patients without the nursing diagnosis. The PV of a defining characteristic, if positive, represents the probability of the nursing diagnosis being present in patients with a specific defining characteristic. If negative, this measure represents the probability of the absence of a nursing diagnosis in patients without this defining characteristic. The likelihood ratio represents the probability of the presence or absence of a defining characteristic in patients with the nursing diagnosis, divided by the probability of this characteristic in patients without the nursing diagnosis.

\section{Results}

The mean length of hospitalization of the children in the sample was 8.29 days ( \pm 1.58$) ; 58.1 \%$ were male, with a mean age of 20.35 months $( \pm 3.11)$. The most frequent 


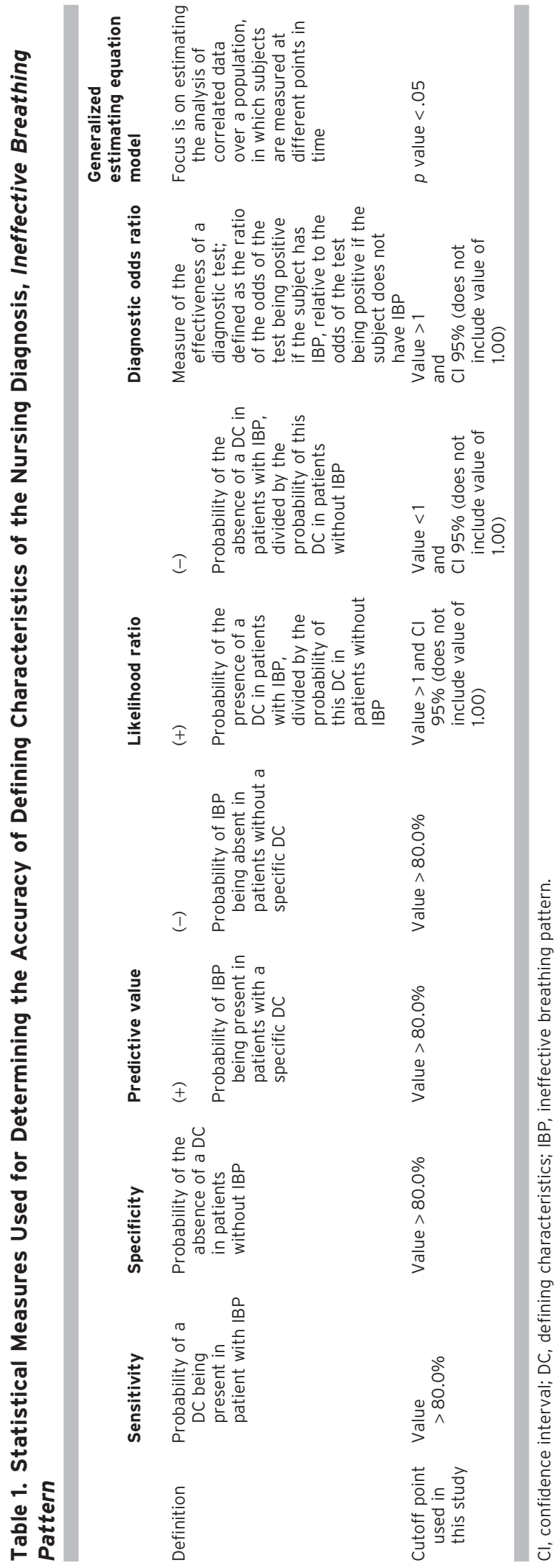

medical diagnosis was pneumonia (85.3\%); however, some children (11.8\%) were admitted without specifying the type of respiratory infection, and in some cases they had more than one type of medical diagnosis. The highest percentage of children with IBP was observed on the first day of assessment $(64 \%)$. This value decreased until the seventh day $(24.6 \%)$, followed by a slight increase on the eighth day (30.9\%) and the ninth day (35.5\%).

Figure 1 presents the distribution of the defining characteristics of IBP during the period in which the research was conducted. During the first assessment, the defining characteristics, alterations in depth of breathing and dyspnea, presented frequencies greater than $75 \%$. However, other defining characteristics also showed high percentage values, approximately 61\%, such as orthopnea, tachypnea, and use of accessory muscles to breathe. Alterations in depth of breathing and tachypnea presented the lowest variation in the percentage values throughout the research period.

The GEE model showed that IBP was associated with the following defining characteristics: alterations in depth of breathing $(p<.001$, OR $=73.32)$, increased anteriorposterior diameter $(p<.001, \mathrm{OR}=31.56)$, altered chest excursion $(p<.001, \mathrm{OR}=259.14)$, orthopnea $(p<.001$, OR = 30.14), tachypnea ( $p=.001, \mathrm{OR}=5.89)$, and use of accessory muscles to breathe ( $p<.001$, OR $=2,595.06$; Table 2 ).

Based on the result obtained by the GEE model, the accuracy of measurements of the defining characteristics that showed statistical significance were analyzed $(p<.05)$. The defining characteristic that presented the best measures of accuracy for IBP was use of accessory muscles to breathe (Se: 88.84\%; Sp: 99.53\%, PV+: 99.30\%; PV-: $92.23 \%)$. Other characteristics that showed high accuracy were alterations in depth of breathing (high value of Se and PV-), as well as altered chest excursion and orthopnea (high measures of Sp and PV+). However, despite the fact that the defining characteristic, increased anterior-posterior diameter, presented Sp above 70\%, the confidence intervals for likelihood ratios were not statistically significant. These findings can be seen in Table 3 .

\section{Discussion}

The occurrence of the IBP nursing diagnosis in children with ARI can be explained because respiratory infection is a pathological process that contributes to the increase of secretions and interferes with the defense mechanisms of the airways (Tarantino, 2005). This alteration can trigger compensatory mechanisms of adaptation that alter the ventilatory pattern and result in clinical manifestations (dyspnea, orthopnea, use of accessory muscles, nasal flaring, tachypnea, and others) that correspond to the defining characteristics of IBP. In this research, the prevalence of IBP (64\%), obtained in the first assessment, was similar to that observed in a previous study, in which the prevalence was 59.6\% (Andrade, Chaves, Silva, Beltrão, \& Lopes, 2012). 
Figure 1. Defining Characteristics of Ineffective Breathing Pattern During the Research Period of Children With Acute Respiratory Infection $(n=136)$

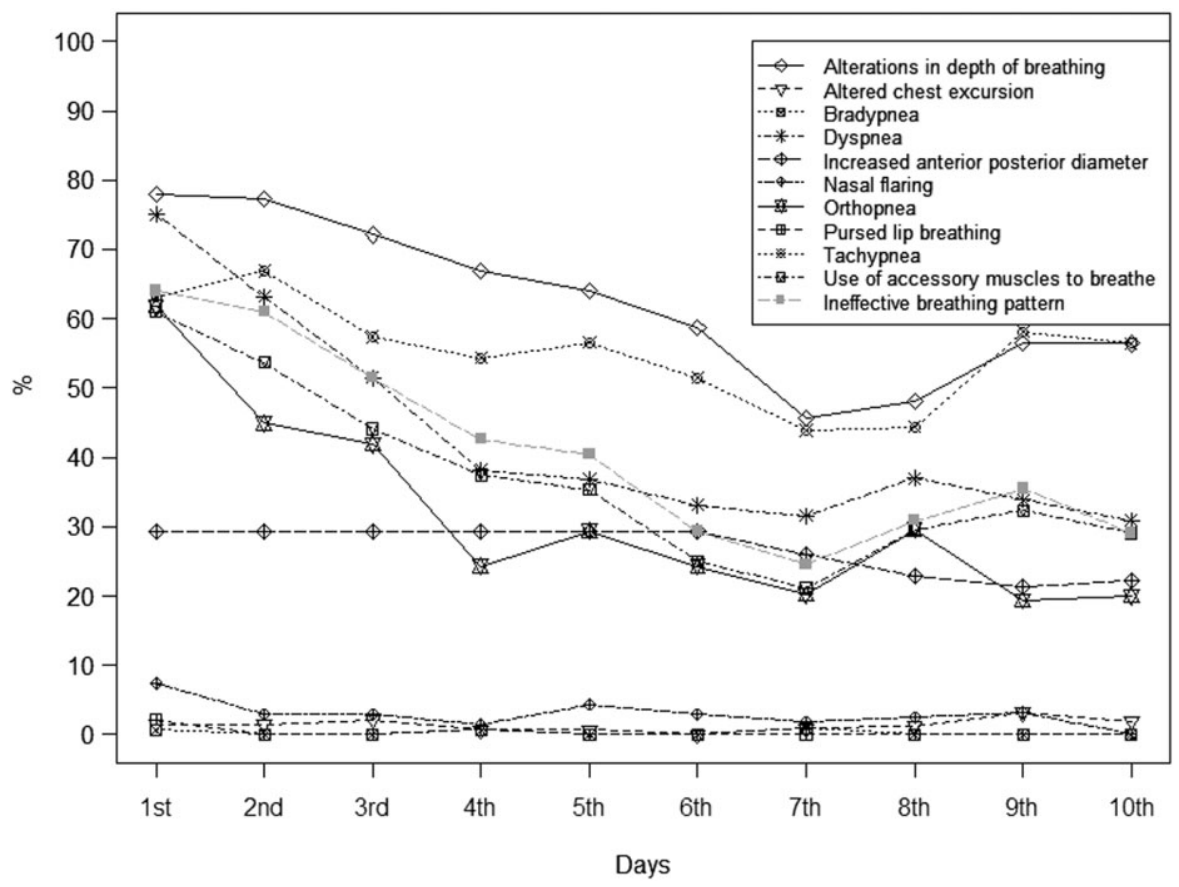

Table 2. Results of the Generalized Estimating Equation Model for All Assessments Using Ineffective Breathing Pattern as the Response Variable (Yes or No), and Entering the Clinical Indicators as Explanatory Variables in the Model (Using ARI)

\begin{tabular}{|c|c|c|c|c|}
\hline Defining characteristics & $p$ value & Odds ratio & $95 \% \mathrm{Cl}$ & \\
\hline Alterations in depth of breathing & $<.001$ & 73.320 & 15.457 & 347.79 \\
\hline Altered chest excursion & $<.001$ & 259.14 & 31.41 & $2,137.92$ \\
\hline Bradypnea ${ }^{a}$ & - & - & - & - \\
\hline Dyspnea & .059 & 3.979 & 0.947 & 16.716 \\
\hline Increased anterior-posterior diameter & $<.001$ & 31.564 & 7.202 & 138.34 \\
\hline Nasal flaring ${ }^{a}$ & - & - & - & - \\
\hline Orthopnea & $<.001$ & 30.149 & 4.490 & 202.43 \\
\hline Pursed lip breathing ${ }^{a}$ & - & - & - & - \\
\hline Tachypnea & .001 & 5.893 & 2.029 & 17.113 \\
\hline Use of accessory muscles to breathe & $<.001$ & $2,595.06$ & 343.88 & $19,583.3$ \\
\hline
\end{tabular}

aNo convergence of the model.

$\mathrm{ARI}$, acute respiratory infection; $\mathrm{Cl}$, confidence interval.

The best measure of accuracy present in this study was use of accessory muscles to breathe, corroborating the findings from a study performed in children with asthma in which measures of accuracy were also more significant for this characteristic (Se: $73.58 \%$, Sp: $90.43 \%, \mathrm{PV}+\mathrm{8} .25 \%$; PV-: 85.86\%; Cavalcante, Mendes, Lopes, \& Lima, 2010). These diseases affect the ventilatory mechanics so that, in some cases, the patient needs to use accessory muscles in an attempt to stabilize respiration (Tarantino, 2005).

Regarding the characteristic, alterations in depth of breathing, no studies were found to enable comparison with the measures of Se and PV- identified in this study. Alterations in depth of breathing can occur when the body attempts to increase the airflow into the respiratory system to combat elevated levels of carbon dioxide and hydrogen ions in the blood, which can be triggered by the obstruction of air passage through the airway as a result of the accumulation of secretions (Marcondes, Vaz, Ramos, \& Okay, 2003).

The defining characteristic, altered chest excursion, presented high Sp (99.84\%) and PV+ (92.31\%) for determination of IBP in children with ARI. In accordance with this 
Table 3. Measures of Accuracy for the Defining Characteristics of the Ineffective Breathing Pattern Diagnosis in Children With Acute Respiratory Infection

\begin{tabular}{|c|c|c|c|c|c|c|c|}
\hline Defining characteristics & Se & Sp & $\mathbf{P V +}$ & PV- & $\mathrm{LR}+(95 \% \mathrm{Cl})$ & LR- $(95 \% \mathrm{Cl})$ & ROC \\
\hline Alterations in depth of breathing & 98.97 & 61.96 & 66.16 & 98.76 & $2.60(2.36-2.87)$ & $0.02(0.01-0.04)$ & 0.804 \\
\hline Altered chest excursion & 2.48 & 99.84 & 92.31 & 57.55 & $15.89(2.24-112.87)$ & $0.98(0.96-0.99)$ & 0.511 \\
\hline Orthopnea & 66.53 & 91.30 & 85.19 & 78.40 & $7.65(5.92-9.88)$ & $0.37(0.32-0.42)$ & 0.789 \\
\hline Tachypnea & 70.04 & 54.97 & 53.90 & 70.94 & $41.56(1.40-1.73)$ & $0.55(0.47-0.64)$ & 0.625 \\
\hline Use of accessory muscles to breathe & 88.84 & 99.53 & 99.30 & 92.23 & $190.71(61.64-590.03)$ & $11.20(0.08-0.14)$ & 0.941 \\
\hline
\end{tabular}

$\mathrm{Cl}$, confidence interval; LR, likelihood ratio; PV, predictive value; ROC, receiver operating characteristic curve; Se, sensibility; Sp, specificity.

finding, a study conducted with patients in the postoperative cardiac phase identified an Sp of $97.3 \%$ (Nascimento, Sousa, Sousa, \& Lopes, 2010). In respect to the ARI, one of the possible relations with this characteristic may be related to the fact that bronchial obstruction (hypersecretion) interferes with the two phases of respiration.

A previous study found different results related to orthopnea, when compared with the present investigation. In children with asthma, a high Se (90\%) and PV- (96\%) were found for diagnosis of IBP. In contrast, children with ARI presented measures of $\mathrm{Sp}$ and a higher $\mathrm{PV}+$ for this defining characteristic (Silveira, Lima, \& Lopes, 2008). The Se value identified by those authors can be related to intrinsic characteristics of the pathophysiology of asthma, in which orthopnea is expected to occur in a higher number of individuals. Therefore, when IBP was present, this characteristic was also identified in a large number of children evaluated. However, the isolated occurrence of orthopnea cannot be considered sufficient to determine the presence of this diagnosis; the manifestation of other defining characteristics is necessary to confirm the presence of IBP.

Despite the statistical significance identified by the GEE model for the defining characteristics of tachypnea and increased anterior-posterior diameter, high values for the measures of accuracy were not found in this research. The result obtained by the GEE model for tachypnea could be related to the fact that the increase in respiratory rate is one of the first responses by the body to try to increase the blood oxygen concentration. Thus, this defining characteristic can be easily identified (Tarantino, 2005).

For the defining characteristic, increased anteriorposterior diameter, the results obtained in this study were different from those of other authors (Cavalcante et al., 2010; Silveira et al., 2008). The value of Sp found in those studies was $96.81 \%$ and $96.88 \%$, respectively. These findings may be related to the fact that asthma is a chronic clinical condition in which the thorax adopts a constant inspiration position as a result of pulmonary hyperinflation. In this situation, the increased lung volume means that higher transthoracic pressures are required to produce changes of the pulmonary volume. These alterations may cause changes so that the anterior-posterior diameter becomes equal to or greater than the transverse diameter (Tarantino, 2005). In this context, the literature indicates that in children under 2 years of age, an increased anteriorposterior diameter is physiologically expected (Seidel et al., 2010); therefore, this finding should be considered with caution. A possible explanation for the lack of statistical significance for the increased anterior-posterior diameter in the present study is the self-limiting nature of the ARI.

Finally, it was noted that the percentage of children with IBP was highest on the first observation, and then decreased daily until a slight increase was noted on days eight and nine. This may signify that this human response presents early and tends to follow the natural course of the ARI. Likewise, it is noted that some of the defining characteristics decrease daily (e.g., alterations in depth of breathing, dyspnea, use of accessory muscles to breathe), others seem to stay constant for a few days before beginning to recede (e.g., increased anterior-posterior diameter), whereas others fluctuate in their occurrence over time (e.g., nasal flaring, orthopnea, tachypnea; Figure 1). Although not the purpose of this research, these types of patterns in the defining characteristics may begin to provide us with an understanding of the clinical course of this nursing diagnosis, and require further study.

\section{Study Limitations}

One of the observed difficulties was the lack of studies in the literature with methodological design similar to this study, which restricted the comparison of results. The age of the study population was considered another limitation because of the difficulty of collecting data in children. In this case, the data collection by persons also responsible for identifying the defining characteristics of IBP increased the subjectivity of responses and could compromise the analysis of results.

The results may have been influenced by incorporation and diagnostic review bias. This happens when prior knowledge about the defining characteristics is incorporated during the diagnostic inference (Zhou, Obuchowski, \& McClish, 2002). Finally, although the information presented in this research contributed to the accurate identification of the IBP diagnosis in children with ARI, these results should be used with caution because most of the children sampled were hospitalized in organizations that received patients 
with a higher probability of manifesting a more severe clinical spectrum.

\section{Conclusion and Implications}

Most of the children in the sample (64\%) presented the nursing diagnosis, ineffective breathing pattern. The most frequent defining characteristics were alterations in depth of breathing, dyspnea, orthopnea, tachypnea, and use of accessory muscles to breathe. The GEE model showed that the presence, together, of the defining characteristics of alterations in depth of breathing, increased anteriorposterior diameter, altered chest excursion, orthopnea, tachypnea, and use of accessory muscles to breathe were associated with an increased chance of occurrence of IBP in children with ARI. Regarding the measures of accuracy, use of accessory muscles to breathe was the most accurate defining characteristic to predict the occurrence of IBP. However, other characteristics also presented high Se measures (alterations in depth of breathing) and Sp (altered chest excursion and orthopnea).

The results of this research can provide educators with a better understanding of the more common defining characteristics in particular patient populations, and those that are more likely to signify the presence of IBP. This can support them in teaching those defining characteristics within those populations, and ensuring that students are aware of the methods to assess for their presence. Students and hospital nurses working with children with ARI can benefit from these results by having evidence as to which defining characteristics they are most likely to identify in practice, therefore being more aware of these characteristics and what they might signify for those in their care. This research method may provide a strategy for identifying those critical defining characteristics recommended by Gordon (1982, 1987).

Further research is necessary to validate these findings in this same population, as well as in other populations in which the diagnosis of IBP is likely to occur. Understanding the clinical course of the diagnosis of ineffective breathing pattern is also necessary to help nurses understand the expected resolution of the diagnosis, to share this information with parents and children, and to monitor the effect of interventions aimed at its improvement. Research on related factors of the diagnosis is also needed, as these will be most effective in directing interventions, as intervention should be aimed at the causative issues underlying the diagnosis.

\section{References}

Andrade, L. Z. C., Chaves, D. B. R., Silva, V. M., Beltrão, B. A., \& Lopes, M. V. O. (2012). Respiratory nursing diagnoses for children with acute respiratory infection. Acta Paulista de Enfermagem, 25(5), 713-720. doi:10.1590/ S0103-21002012000500011

Beltrão, B. A., Silva, V. M., Araujo, T. L., \& Lopes, M. V. O. (2011). Clinical indicators of ineffective breathing pattern in children with congenital heart diseases. International Journal of Nursing Terminologies and Classifications, 22(1), 4-12. doi:10.1111/j.1744-618X.2010.01169.x

Cavalcante, J. C. B., Mendes, L. C., Lopes, M. V. O., \& Lima, L. H. O. (2010). Indicadores Clínicos de Padrão Respiratório Ineficaz em crianças com asma. [Clinical indicators of ineffective breathing pattern in children with asthma]. Revista da Rede de Enfermagem do Nordeste, 11(1), 6675.

Chagas, K. L. M., Lima, L. H. O., Oliveira, E. A. R., \& Luz, G. O. A. (2011). Diagnósticos de enfermagem em crianças com sinais e sintomas respiratórios: um estudo descritivo. [Nursing diagnoses in children with respiratory signs and symptoms: A descriptive study]. Revista da Rede de Enfermagem do Nordeste, 12(2), 302-308.

Fehring, R. J. (1986). Validating diagnostic labels: Standardized methodology. Proceedings of the Conference of North American Nursing Diagnosis Association, USA, 6, 183-190.

Fehring, R. J. (1987). Methods to validate nursing diagnosis. Heart \& Lung, 16(6), 625-629.

Fehring, R. J. (1994). The Fehring model. Proceedings of the Conference of North American Nursing Diagnosis Association, USA, 10, 55-62.

Gordon, M. (1982). Nursing diagnosis: Process and application (1st ed.). New York: McGraw-Hill.

Gordon, M. (1987). Nursing diagnosis: Process and application (2nd ed.). New York: McGraw-Hill.

Grant, J. S., \& Kinney, M. R. (1992). Clinical referents for nursing diagnoses. Journal of Neuroscience Nursing, 24(2), 94-98.

Herdman, T. H. (Ed.) (2012). NANDA international nursing diagnoses: Definitions and classification, 2012-2014. Oxford, UK: Wiley-Blackwell.

Herdman, T. H., \& Von Krogh, G. (2012). The NANDA international taxonomy II, 2012-2014. In T. H. Herdman (Ed.), NANDA International nursing diagnoses: Definitions and classification, 2009-2011 (pp. 49-65). Oxford, UK: Wiley-Blackwell.

Jarvis, C. (2011). Physical examination and health assessment (6th ed.). St Louis, MO: Elsevier Saunders.

Kestenbaum, B. (2009). Epidemiology and biostatistics: An introduction to clinical research. London: Springer.

Kinney, M., \& Guzzetta, C. E. (1989). Identifying critical defining characteristics of nursing diagnoses using magnitude estimation scaling. Research in Nursing and Health, 12(6), 373-380.

Knottnerus, A., \& Buntinx, F. (2009). The evidence base of clinical diagnosis. Oxford, UK: Blackwell Publishing.

Lopes, M. V. O., Silva, V. M., \& Araujo, T. L. (2012). Methods for establishing the accuracy of clinical indicators in predicting nursing diagnoses. International Journal of Nursing Knowledge, 23(3), 134-139. doi:10.1111/j.20473095.2012.01213.x

Marcondes, E., Vaz, F. A. C., Ramos, J. L. A., \& Okay, Y. (2003). Pediatria básica: Pediatria clínica geral, tomo II (9th ed.). [Basic pediatrics: General clinical pediatrics, (Vol II)]. São Paulo, Brazil: SARVIER.

Martins, I., \& Gutiérrez, M. G. R. (2005). Intervenções de enfermagem para o diagnóstico de enfermagem Desobstrução ineficaz de vias aéreas. [Nursing interventions for the nursing diagnosis, ineffective airway clearance]. Acta Paulista de Enfermagem, 18(2), 143-149.

Monteiro, F. P. M., Silva, V. M., \& Lopes, M. V. O. (2006). Diagnósticos de enfermagem identificados em crianças com infecção respiratória aguda. [Nursing diagnoses identified in children with acute respiratory infection]. Revista Eletrônica de Enfermagem, 8(2), 213-221. Retrieved October 10, 2009, from http://www.fen.ufg.br/revista/revista8_2/ v8n2a06.htm

NANDA-I. (2012). Definition of a nursing diagnosis, revised by the membership during the business meeting of the 2012 conference (Board meeting minutes, May 2012). Retrieved from http://www.nanda.org/Portals/o/ PDFs/Leadership/NANDA-I-Book-of-Reports-May-2012.pdf

Nascimento, R. V., Sousa, T., Sousa, V. E. C. \& Lopes, M. V. O. (2010). Acurácia do diagnóstico de enfermagem padrão respiratório ineficaz em pacientes no pós-operatorio Cardíaco. [Accuracy of the nursing diagnoses, ineffective breathing pattern, in post-operative cardiac patients]. In: $10^{\circ}$ Simpósio Nacional de Diagnóstico em Enfermagem (Sinaden), Brasília.

Potter, P. A., \& Perry, A. G. (2004). Fundamentals of nursing (6th ed.). St Louis, MO: Mosby.

Seidel, H. M., Ball, J. W., Dains, J. E., Flynn, J. A., Solomon, B. S., \& Stewart, R. W. (2010). Mosby's guide to physical examination (7th ed.). St. Louis, MO: Elsevier.

Silva, V. M., Lopes, M. V. O., Araujo, T. L., Beltrão, B. A., Monteiro, F. P. M., Cavalcante, T. F., ... Santos, F. A. A. S. (2011). Operational definitions of outcome indicators related to ineffective breathing patterns in children with congenital heart disease. Heart Lung, 40, e70-e77.

Silva, V. M., Lopes, M. V. O., Araujo, T. L., Ciol, M. A., \& Carvalho, E. C. (2008). Clinical indicators of ineffective airway clearance in children with congenital heart disease. Journal Clinical Nursing, 18, 729-736. 
Silveira, U. A., Lima, L. H. O., \& Lopes, M. V. O. (2008). Características definidoras dos diagnósticos de enfermagem Desobstrução Ineficaz das Vias Aéreas e Padrão Respiratório Ineficaz em crianças asmáticas. [Defining characteristics of the nursing diagnoses, ineffective airway clearance and ineffective breathing pattern, in asthmatic children]. Revista da Rede de Enfermagem do Nordeste, 9(4), 125133.

Sousa, V. E. C., Lopes, M. V. O., Araujo, T. L., Rolim, I. L. T. P., Nascimento, R. V., \& Oliveira, T. F. (2013). Clinical indicators of ineffective airway clearance for patients in the cardiac postoperative period. European Journal of Cardiovascular Nursing, 12(2), 193-200. doi:10.1177/ 1474515112443931

Swartz, M. H. (2005). Textbook of physical diagnosis: History and examination (5th ed.). St Louis, MO: Saunders.
Tarantino, A. B. (2005). Sistema respiratório. [Respiratory system]. In C. C. Porto (Ed.), semiologia médica (4th ed., pp. 321-417). Rio de Janeiro: Guanabara Koogan.

Van Belle, G., Fisher, L. D., Heagerty, P. J., \& Lumley, T. (2004). Biostatistics: A methodology for the health sciences. Hoboken, NJ: John Wiley \& Sons. Vargas, L. C. O. (2011, June). Rasch method for validation of nursing diagnosis: A way forward? Proceedings of the NANDA International Latin American Symposia: 2011, São Paulo, Brazil.

Yorke, J., Horton, M., \& Jones, P. W. (2012). A critique of Rasch analysis using the dyspnoea-12 as an illustrative example. Journal of Advanced Nursing 68(1), 191-198. doi:10.1111/j.1365-2648.2011.05723.x

Zhou, X., Obuchowski, N. A., \& McClish, D. K. (2002). Statistical methods in diagnostic medicine. New York: Wiley Interscience. 